\title{
The Telephone Interview for Cognitive Status
}

(Cogn Behav Neurol 2018;31:160-167)

$\mathrm{t}$ is difficult to think back to the time before the ubiquity of the Internet, smartphones, remote sensors, and the like. For researchers, this technology has opened up many novel and convenient ways to evaluate and monitor study participants. However, the whole idea of remote testing had to start somewhere. The article by Brandt and colleagues (Brandt et al, 1988) introducing the Telephone Interview for Cognitive Status is a classic because the authors had the vision to create an instrument that could be administered remotely. While relying on the now "antiquated" technology of the simple phone call, the Telephone Interview for Cognitive Status met a pressing need, and helped to convince the field that this form of remote testing is valid, reliable, and practical. In fact, the value of the Telephone Interview for Cognitive Status has persisted even in the face of more modern technology, most likely because the person-to-person exchange provides a human touch and ensures cooperation. Thirty years after publication of this seminal article, the authors certainly deserve recognition for their imagination and foresight.

Yaakov Stern, PhD

ys11@columbia.edu

Department of Neurology

Columbia University College of Physicians and Surgeons

New York, New York

\section{REFERENCE}

Brandt J, Spencer M, Folstein M. 1988. The Telephone Interview for Cognitive Status. Neuropsychiatry Neuropsychol Behav Neurol. 1:111-117.
Received for publication September 4, 2018; accepted September 4, 2018. Commentary on: Brandt J, Spencer M, Folstein M. 1988. The Telephone Interview for Cognitive Status. Neuropsychiatry Neuropsychol Behav Neurol. 1:111-117.

The commentator declares no conflicts of interest.

Copyright (C) 2018 Wolters Kluwer Health, Inc. All rights reserved. 